\title{
Training for Lateral Acceleration
}

\author{
Doug Enga \& Bharathan Sundar
}

aLesley University, Cambridge MA, USA.

\begin{abstract}
Tennis movement can be characterized by primarily short lateral bursts over typically 3-4 $\mathrm{m}$ initiated by a reactive decision step. Lateral acceleration depends on unilateral movement, or specifically, the outside leg to enhance ground reaction force (GRF). Few studies have been conducted for the development of lateral speed with emphasis on unilateral training. A simple one-leg test for unilateral strength is presented. Exercises for improving lateral acceleration are presented.
\end{abstract}

\begin{abstract}
Key words: lateral movement, acceleration, unilateral leg strength, change of direction, training
\end{abstract}

Received: 22 January 2021

Acepted: 19 March 2021

Corresponding author: Doug Eng. Lesley University (29 Everett Street, Cambridge, MA 02138).

Email: douglas.w.eng@gmail.com

\section{INTRODUCTION}

Tennis movement can be characterized by primarily short lateral movements initiated by a reactive decision step (aka, split-step). About $70 \%$ of tennis movement is lateral and $20 \%$ of tennis movement is forward (Weber et al., 2007). Movement can be improved by: 1) strength-speed training, 2) technical training, 3) and anticipation training. Kovacs (2009) summarized the importance of lateral movement training. This article addresses on-court lateral acceleration with regards to strength-speed training.

\section{Movement and Acceleration}

It has been estimated that the average professional on clay courts runs to only $5 \%$ of shots where distance $>4.5$ m (Ferrauti, \& Weber, 2001). Sl.com staff (2015) tracked movement of 4 ATP players and found their movement per point was 8 - $14 \mathrm{~m}$ which depended on playing style and rally length. At the 2017 Australian Open, the average rally lasted 4.47 and 4.85 shots and 5.44 and $5.93 \mathrm{~s}$ for women and men, respectively (Carboch et al., 2018). Top ATP $(\mathrm{N}=34)$ and WTA $(\mathrm{N}=44)$ players had mean rally lengths of 4.21 and 4.06 shots with a player range from 3.2 - 5.4 during September 2019 September 2020 (Sackmann, n.d.a; Sackmann, n.d.b). It has been reported that inter-point time is $25-45 \mathrm{~s}$ and varies with individuals (Bialik, 2014; Sackmann, 2020). From data, it is estimated that a run $>4.5$ m occurs once every $3-3.5$ min.

Although runs $>4.5 \mathrm{~m}$ occur infrequently, high acceleration and deceleration are more common. Hoppe et al. (2014) found peak running speeds for adolescent players (12-14 y.o.) was $4.4 \pm 0.8 \mathrm{~m} / \mathrm{s}$ (9.8 mph). Players exceeded $3 \mathrm{~m} / \mathrm{s}$ (6.71 $\mathrm{mph}$ ) once every $5 \mathrm{~min}$ or only 18.5 times per match. High acceleration (> $2.0 \mathrm{~m} / \mathrm{s} 2$ ) and deceleration was 51.7 and 47.0 times per match, respectively or $0.6 / \mathrm{min}$ each or once per 1.7 $\mathrm{min}$. High acceleration at once per $1.7 \mathrm{~min}$ is twice as frequent as running distances $>4.5 \mathrm{~m}$ as reported for professional players.

Clearly, initial acceleration is more important than top end speed. In addition, anticipatory cues can optimize movement and reduce acceleration requirements by responding earlier to a stimulus. Lateral acceleration depends on unilateral movement, or specifically, the outside leg to enhance GRF (ground reaction force). Technical footwork training should involve training unilateral explosiveness to improve RFD (rate of force development). In the 5 - 10 m interval, an athlete can reach $70 \%$ of top end speed (Duthie, Pyne, Marsh, \& Hooper, 2006).

\section{Lateral Acceleration}

Of interest is the acceleration of top professional tennis players. Djokovic and Nadal have been measured at 4.81 and $4.70 \mathrm{~m} / \mathrm{s} 2$ in acceleration to the forehand (Eng \& Sundar, 2020). Nadal was measured at $4.30 \mathrm{~m} / \mathrm{s} 2$ in acceleration to the backhand. Comparatively, Usain Bolt in a starting 4-point stance has been calculated to reach an initial acceleration of $9.5 \mathrm{~m} / \mathrm{s} 2$ (Gómez et al., 2013). A sprinter's first 3 steps involves mostly horizontal force (Dintiman, 2020). However, Djokovic and Nadal are sprinting repeatedly and Bolt is sprinting once, and the distances in tennis and the $100 \mathrm{~m}$ sprint do different demands. On wide balls, Djokovic can typically achieve stride lengths of $2 \mathrm{~m}$ and stride frequencies of 4 steps/sec (Eng \& Sundar, 2020). Acceleration was not uniform but dependent on unilateral RFD. An athlete may initially drive from either leg unevenly as leg force may not be equal for either leg. In addition, legs may be in different phases such as the takeoff or touchdown positions.

Few studies have been conducted with the development of lateral speed. Players typically run 0.25 to $0.50 \mathrm{~m}$ more to the forehand side than the backhand side (Weber et al., 2007). Therefore, training acceleration to the forehand may be more important for players who prefer to hit a dominant forehand. Hewit et al. (2012) discussed unilateral leg movement in linear and lateral jumping and running. Largest leg strength differences were found in lateral movement (single leg countermovement lateral jumps or SLCM-L) but it was suggested that up to $15 \%$ difference was normal and acceptable. That is, an athlete might be $15 \%$ weaker in one leg than the other without detrimental loss of speed. Unlike many 
field sports which involve cutting at $20-60^{\circ}$ where asymmetric leg strength is not consequential, tennis, however, differs and requires greater lateral movement and $180^{\circ} \mathrm{COD}$ (change of direction).

In lateral movement, most force is generated by the outside leg which is farther from the intended direction. After the stroke, recovery to a favorable court position requires where the legs switch roles. Tennis players can be tested on the outside leg moving either to the forehand or backhand side. Using unilateral strength and plyometric training to train unilateral leg force production may improve athletes with weaker movement to one side.

\section{Testing Method}

Measurement of initial leg power can be correlated to leg strength. Hewit et al. (2012) tested various vertical and lateral jumps finding the largest leg discrepancies were SLCM-L (single leg countermovement jump - lateral). Modest correlation between lateral power and COD has been found but lateral jumps were not the strongest predictors of COD speed (Lockie et al., 2014). Lockie et al. (2013) developed tests for COD cutting at $20-60^{\circ}$ which is valid for many field sports but tennis requires $180^{\circ}$. COD has been found to be related to the outside reactive leg strength (Young et al., 2002). Athletes averaging $24 \%$ stronger in the right leg, were $4 \%$ faster moving to the left. Habibi et al. (2010) found single leg hop power was correlated with $10 \mathrm{~m}$ sprints. Therefore, unilateral leg reactive strength is important for tennis.

Figure 1 shows a SLLJ (single leg lateral jump) in which a countermovement is allowed and the takeoff and touchdown leg are the same. The SLLJ can off either leg can be a test for unilateral leg strength. Measurements should be on the outside edge of the foot or shoe (green line). Lateral jumps in both directions should be executed and measure from a best of three jumps.

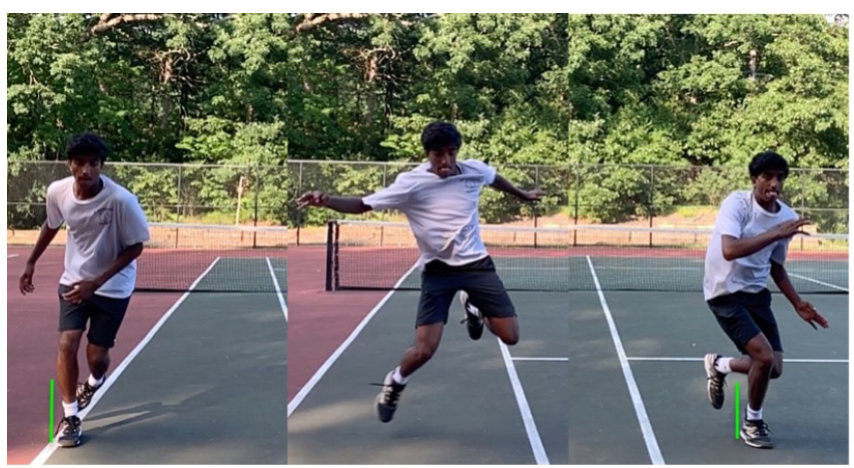

Figure 1. Single leg lateral jump (SLLJ) test with countermovement. Note the same leg is used for takeoff and touchdown.

\section{EXERCISES}

\section{Lateral Wall Holds and Drives}

Lateral wall drills allow the athlete to shift the center of gravity applying horizontal lateral force, while maintaining balance using a wall or fence. In the lateral wall hold (Figure 2 ), the athlete leans $30^{\circ}$ sideways into a wall placing a hand out for support or the athlete can lean on the shoulder. The athlete lifts either knee up to the hips and maintains the angle for a few seconds and switch to the other leg and hold that position for a few seconds. The athlete repeats leaning on the other side. Once the athlete is proficient, the athlete can do lateral wall drives in sets of 2-6 rapid alternating steps. The athlete then switches to the other side.

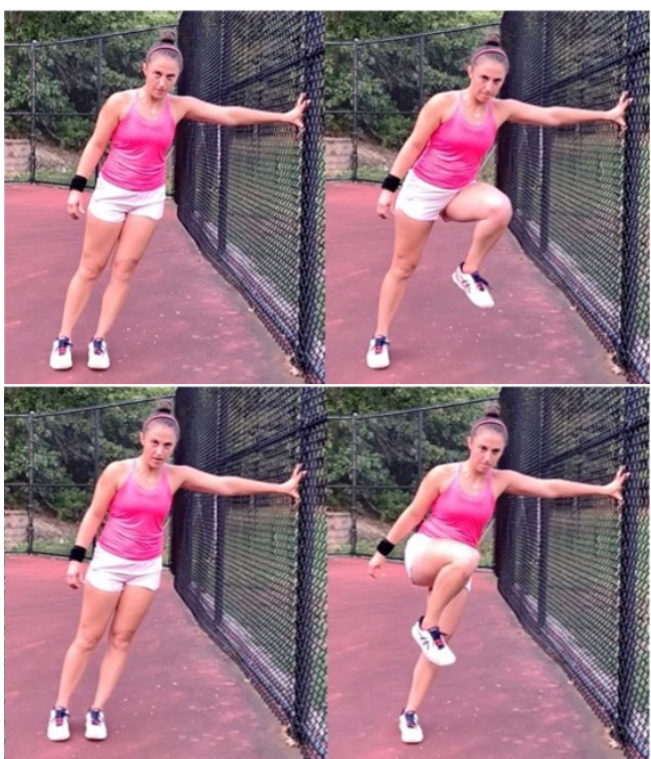

Figure 2. Lateral wall hold and alternating drives.

A third wall drill (Figure 3 ) is the load and crossover hold which brings the outside leg across and up. Force production is more powerful and angled than in the lateral wall hold. Athlete should start low with the outside leg at an angle to push off. The inside shin is slightly tilted. The athlete drives quickly into the wall. Both arms can be placed on the wall or fence. Hold the starting and ending positions for a few seconds. Sets of 10 can be done on both sides.

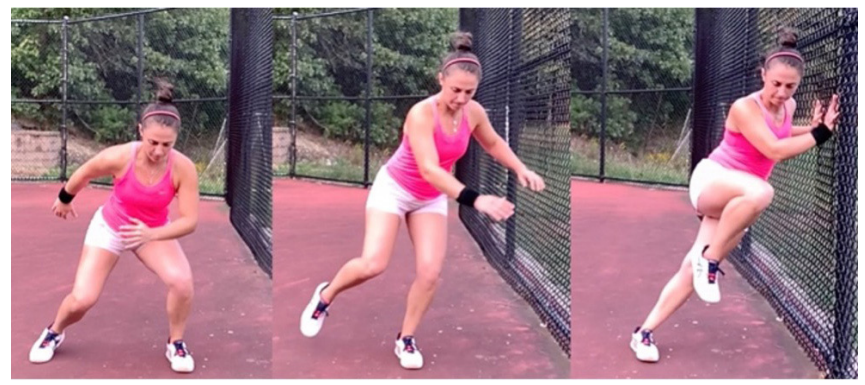

Figure 3. Load and crossover hold.

Hops + Bounds + Sprints

A hop is defined when the take-off and touchdown is done off the same leg and the distance covered is relatively small. A jump can be two-leg or one leg for both take-off and touchdown covering larger distances than a hop. A bound is defined when the take-off leg and touchdown leg are alternating legs.

Most decision steps in tennis involve a vertical component with landing first on the leg farther away from the intended direction and the other leg taking a lateral step with the toe pointing towards the intended direction. For training, the following exercises are useful:

A. Vertical single leg hop + lateral bound (alternating), shown in Figure 4

B. Lateral single leg hop + lateral bound (alternating) 
C. Vertical single leg hop + lateral bound + short sprint opposite direction

D. Lateral single leg hop + lateral bound + short sprint opposite direction, shown in Figure 5
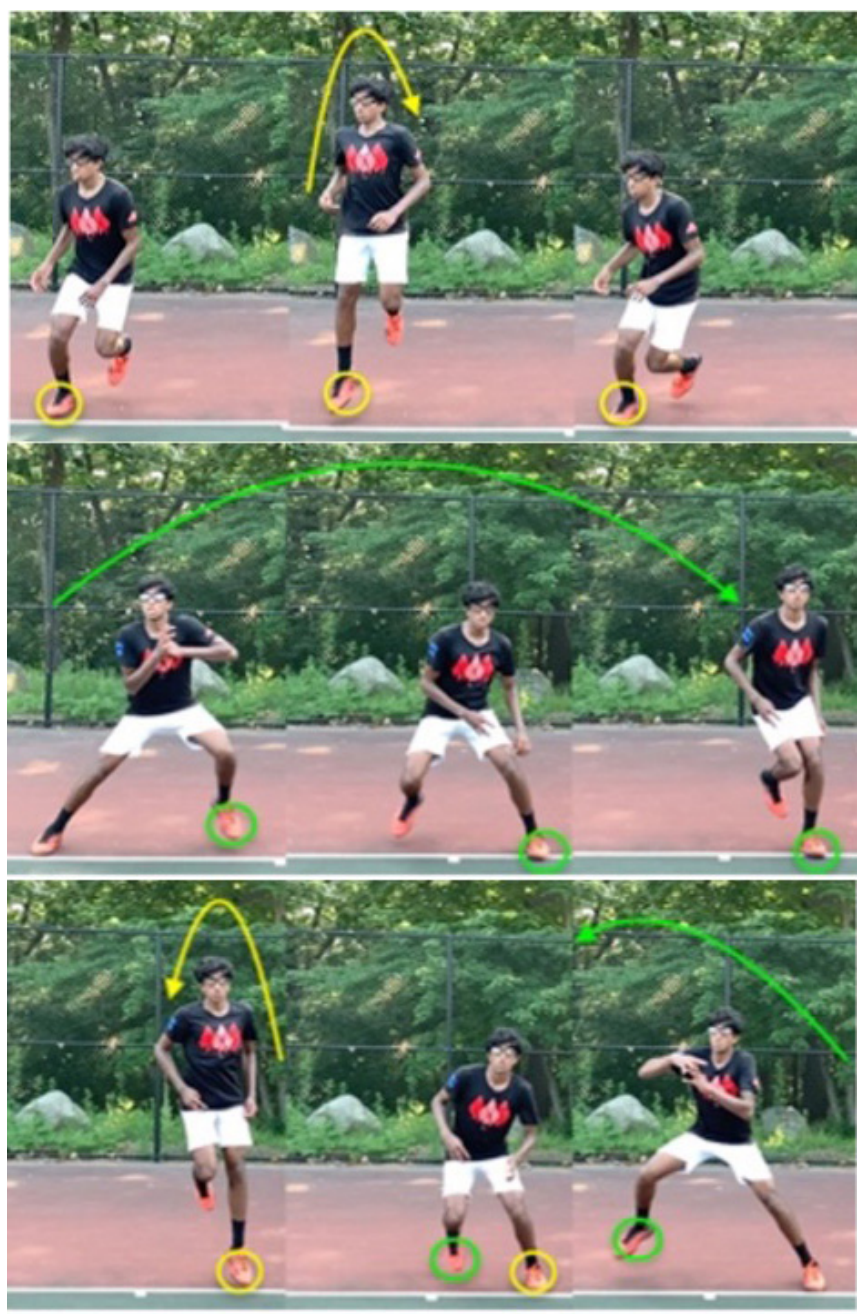

Figure 4. Vertical single leg hop + lateral bound (alternating).

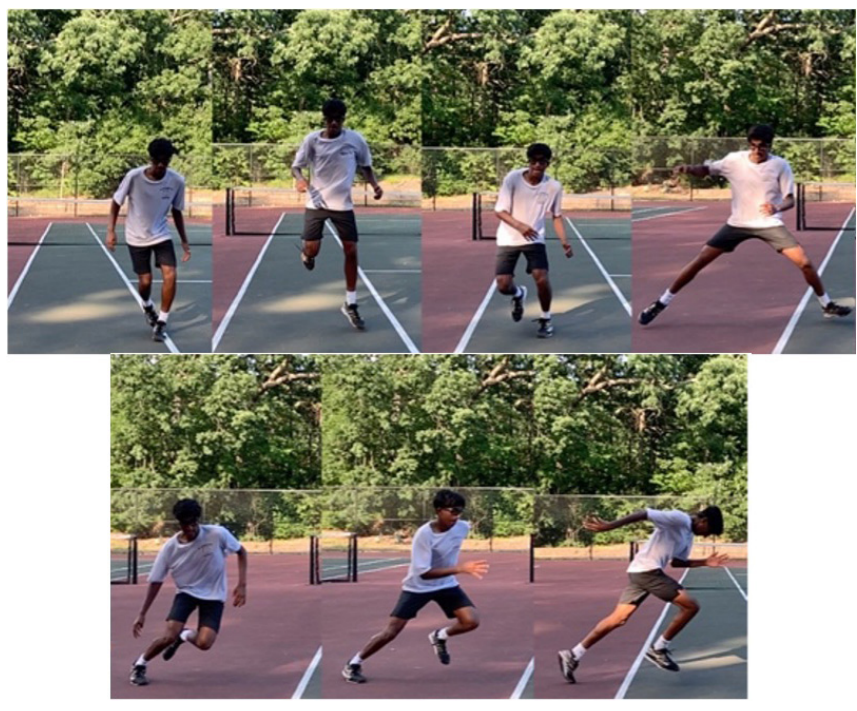

Figure 5. Lateral single leg hop + lateral bound + short sprint opposite direction.
In these exercises, the single leg hops mimics the initial decision step landing but trains single-leg RFD for the lateral bound. One purpose of varying vertical and lateral single leg hops is the variability in tennis movement. At times a player may be starting from a moving position or a standing position as in the serve return. In standing positions, the initial decision step may have a more vertical force. Other times a player may be still recovering into the court at higher velocities, where a decision step may involve a greater horizontal force. In such case, greater forces are required for COD. Therefore, lateral hops combined with lateral bounds can help train those COD movements.

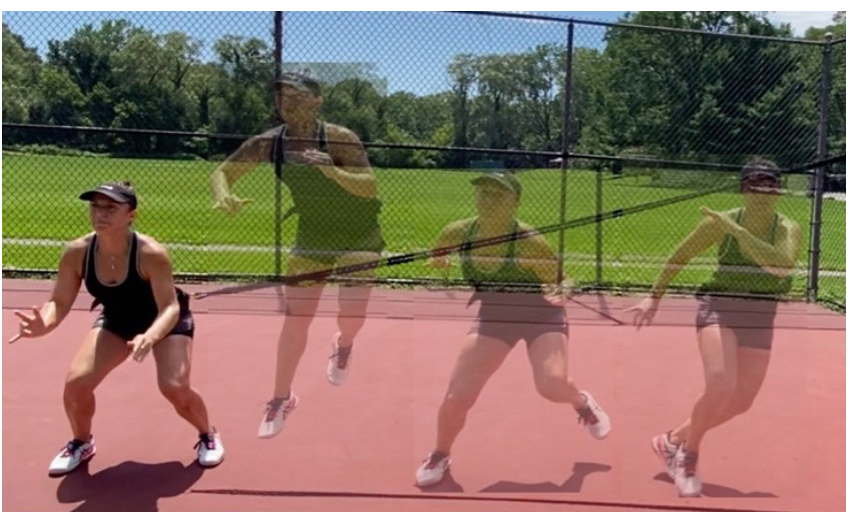

Figure 6. Bungee-assisted lateral explosion

Another important concept is developing appropriate leg stiffness with short GCT or ground contact time (Ferris et al., 1999; Morin et al., 2007). Therefore, rapid movement quality with short GCT is important. In Figure 5, the athlete rapidly shifts weight inside after the lateral bound to sprint in the opposite direction of the bound. Exercises A (Figure 4) and $B$ can be done with 12-20 reps. Exercises $C$ and $D$ (Figure 5) can be done in sets of 6-10 reps with a short break between reps. Exercises $C$ and $D$ may be combined with other COD and agility exercises to train repeated sprint ability (RSA).

\section{Contrast Training}

Contrast training refers to varying loads with similar movement or exercises. A classic contrast training for speed involves running uphill and downhill at modest angles as not to alter running mechanics (Dintiman, 2020). Bungees and resistance bands can provide assistance or resistance forces without significantly altering lateral movement. Figure 6 shows the bungee-assisted lateral explosion. Anchor the bungee high so it pulls the athlete laterally and upwards. The athlete makes a decision step into a crossover step with 2-3 extra accelerating strides. In the bungee-resisted lateral explosion, the bungee is anchored at the bottom of the fence and the athlete explodes upwards and away from the anchor into a crossover step with 2-3 extra accelerating strides. An athlete may do sets of 8-10 reps of resisted and assisted accelerations.

\section{CONCLUSIONS}

Tennis movement is mostly lateral but athletes may have differences in movement to either side which should be trained. Tennis players who use the forehand weapon to cover most of the court may require higher acceleration to the forehand. Little research exists on unilateral reactive leg strength training which has implications in tennis. Physical 
training should require elastic unilateral reactive leg strength training and COD movement. Tennis-specific physical oncourt training for lateral acceleration was tackled with regards to technical training. A single leg lateral jump test is recommended but needs to be correlated to actual lateral acceleration in future studies. Lateral wall exercises, hopjump-bound exercises and contrast training may help tennis players improve lateral movement.

\section{REFERENCES}

Bialik, K. (2014 July 2). Does tennis need a shot clock? Retrieved 7 September 2020 from https://fivethirtyeight.com/features/does-tennis-need-a-shotclock/

Carboch, J., Placha, K., \& Sklenarik, M. (2018). Rally pace and match characteristics of male and female tennis matches at the Australian Open 2017. Journal of Human Sport and Exercise, 13(4), 743-751. https://doi.org/10.14198/jhse.2018.134.03

Dintiman, G. (2020). NASE essentials of next-generation sports speed training. Healthy Learning.

Duthie, G. M., Pyne, D. B., Marsh, D. J., \& Hooper, S. L. (2006). Sprint patterns in rugby union players during competition. Journal of Strength and Conditioning Research, 20(1), 208. https://doi.org/10.1519/00124278-200602000-00034

Eng, D., \& Sundar, B. (2020 October 7). Lateral Acceleration: Djokovic, Nadal and On-Court Training, Part 1. International Tennis Performance Association. http://itpa-tennis.org/itpa-blog.htm

Ferris, D. P., Liang, K., \& Farley, C. T. (1999). Runners adjust leg stiffness for their first step on a new running surface. Journal of Biomechanics, 32(8), 787794. https://doi.org/10.1016/s0021-9290(99)00078-0

Gómez, J. H., Marquina, V., \& Gómez, R. W. (2013). On the performance of Usain Bolt in the $100 \mathrm{~m}$ sprint. European Journal of Physics, 34(5), 1227. https://doi.org/10.1088/0143-0807/34/5/1227

Habibi, A., Shabani, M., Rahimi, E., Fatemi, R., Najafi, A., Analoei, H., \& Hosseini, M. (2010).

Relationship between jump test results and acceleration phase of sprint performance in national and regional $100 \mathrm{~m}$ sprinters. Journal of Human Kinetics, 23(2010), 29-35. https://doi.org/10.2478/v10078-010-0004-7

Hewit, J. K., Cronin, J. B., \& Hume, P. A. (2012). Asymmetry in multidirectional jumping tasks. Physical Therapy in Sport, 13(4), 238-242. https://doi.org/10.1016/j.ptsp.2011.12.003
Hoppe, M. W., Baumgart, C., Bornefeld, J., Sperlich, B., Freiwald, J., \& Holmberg, H. C. (2014). Running activity profile of adolescent tennis players during match play. Pediatric Exercise Science, 26(3), 281-290. https://doi.org/10.1123/pes.2013-0195

Kovacs, M. S. (2009). Movement for tennis: The importance of lateral training. Strength \& Conditioning Journal, 31(4), 77-85. https://doi.org/10.1519/ssc.0b013e3181afe806

Lockie, R. G., Schultz, A. B., Callaghan, S. J., Jeffriess, M. D., \& Berry, S. P. (2013). Reliability and validity of a new test of change-of-direction speed for field-based sports: the change- of-direction and acceleration test (CODAT). Journal of Sports Science and Medicine, 12(1), 88. https://doi.org/10.3390/sports7020045

Lockie, R. G., Schultz, A. B., Callaghan, S. J., Jeffriess, M. D., \& Luczo, T. M. (2014). Contribution of leg power to multidirectional speed in field sport athletes. Journal of Australian Strength and Conditioning, 22(2), 16-24. https://www.researchgate.net/profile/Eamonn_Flanagan/ publication/265227430_Researc hed_Applications_of_Velocity_Based_ Strength_Training/links/543690a60cf2dc341db35 e79.pdf\#page $=17$

Morin, J. B., Samozino, P., Zameziati, K., \& Belli, A. (2007). Effects of altered stride frequency and contact time on leg-spring behavior in human running. Journal of Biomechanics, 40(15), 3341-3348. https://doi.org:10.1016/j.jbiomech.2007.05.001

Sackmann, J. (n.d.a). Match charting project: Men's rally leaders: Last 52. Retrieved 7

September 2020 from http://tennisabstract.com/reports/mcp_leaders_rally_ men_last52.html

Sackmann, J. (n.d.b). Match charting project: Women's rally leaders: Last 52. Retrieved 7

September 2020 from http://tennisabstract.com/reports/mcp_leaders_rally_ women_last52.html

Sackman, J. (2020 August 31). What happens to the pace of play without fans, challenges or towelkids? http://www.tennisabstract.com/blog/category/ match-length/ Si.com Staff (2015 January 25). Daily data viz: Mens court distance covered. https://www.si.com/tennis/2015/01/25/daily-data-vizmens-court-distance-covered-australian-open

Young, W. B., James, R., \& Montgomery, I. (2002). Is muscle power related to running speed with changes of direction? Journal of Sports Medicine and Physical Fitness, 42(3), 282-288. https://www.researchgate. net/profile/Warren_Young/publication/11281917 Is Muscle Power_Related_to_Running_Speed_With_Changes_of_Direction/ links/Odeec529cfa284fa7d000000.pdf

Weber, K., Pieper, S., \& Exler, T. (2007). Characteristics and significance of running speed at the Australian Open 2006 for training and injury prevention. Journal of Medicine and Science in Tennis, 12(1), 14-17. https://www.tennismedicine.org/page/JMST

Copyright $(2021$ Doug Eng \& Bharathan Sundar

\section{() (i)}

This text is under a Creative Commons BY 4.0 license

You are free to Share - copy and redistribute the material in any medium or format - and Adapt the content - remix, transform, and build upon the material for any purpose, even commercially under the following terms:

Attribution: You must give appropriate credit, provide a link to the license, and indicate if changes were made. You may do so in any reasonable manner, but not in any way that suggests the licensor endorses you or your use. 